\title{
Adjunctive zonisamide therapy in the long-term treatment of children with partial epilepsy: Results of an open-label extension study of a phase III, randomized, double-blind, placebo-controlled trial
}

\author{
*Renzo Guerrini, *Anna Rosati, $\uparrow$ Kate Bradshaw, and $\uparrow$ Luigi Giorgi \\ Epilepsia, 55(4):568-578, 2014 \\ doi: $10.1111 /$ epi.12548
}

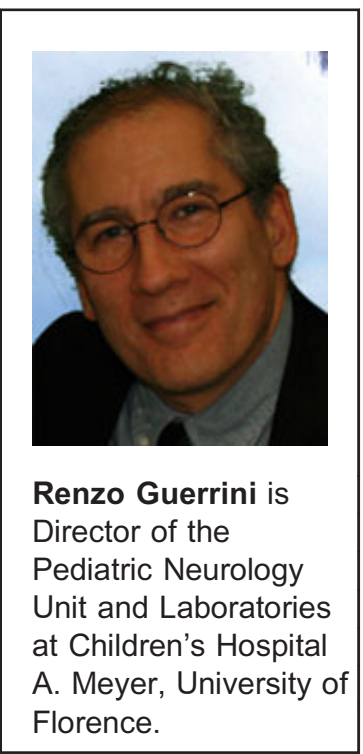

\begin{abstract}
SUMMARY
Objective: To investigate the safety/tolerability and efficacy of long-term adjunctive zonisamide and its impact on growth and development in children (6-18 years) with partial epilepsy.

Methods: Open-label extension of a phase III, placebo-controlled trial. Started with double-blind transition period (2-I I weeks), during which patients on zonisamide continued at the same dose and those on placebo switched to zonisamide $1 \mathrm{mg} / \mathrm{kg} / \mathrm{day}$, up-titrated to $8 \mathrm{mg} / \mathrm{kg} /$ day (maximum $500 \mathrm{mg} /$ day). During the subsequent open-label period (4557 weeks), zonisamide dosing could be adjusted according to tolerability/response. Safety assessments included treatment-emergent adverse events (TEAEs), clinical laboratory parameters, and vital signs. Efficacy assessments included responder rate (primary assessment) and seizure freedom rate during the open-label period. Growth and development assessments comprised Tanner stages, hand x-rays, Child Behavior Checklist (CBCL 6/ 18), School Performance questionnaire, Physician and Parent/Guardian Global Impression of Change, and Controlled Oral Word Association Test (COWAT).

Results: One hundred forty-four children entered the study; 99 (68.8\%) of I 44 children completed it, and $108(75.0 \%)$ of I 44 received zonisamide for $\geq$ I year. TEAEs occurred in $39(27.1 \%)$ of 144 patients. There were low incidences of serious TEAEs $(2.1 \%)$ and TEAEs leading to discontinuation (2.8\%). Bicarbonate level decreases $>3.5 \mathrm{~mm}$ occurred in 64 patients $(44.4 \%)$, and 24 patients $(16.7 \%)$ had a weight decrease of $\geq 10 \%$ from baseline. During the open-label period, 8 I (56.3\%) of I 44 patients were responders and 16 (II.1\%) of 144 achieved seizure freedom. Tanner staging and skeletal development were as expected for the study population. Changes were minimal for CBCL $6 / 18$ and School Performance scores. Most patients were "much improved"/"very much improved" on Physician (73.8\%) and Parent/Guardian (75.4\%) Global Impressions of Change. Median changes in COWAT Category and Letter Fluency scores were 2.0 and 0.5 , respectively.

Significance: Adjunctive zonisamide was well tolerated and efficacious over a period of at least I year in children with partial epilepsy, with no unexpected safety concerns and no consistent detrimental effects on growth and development.

KEY WORDS: Development, Growth, Partial seizures, Pediatric epilepsy, Safety/tolerability, Zonisamide.
\end{abstract}

\footnotetext{
Accepted January 3, 2014; Early View publication Feburary 22, 2014.

*Pediatric Neurology Unit and Laboratories, Department of Neuroscience, Pharmacology and Child Health, Children's Hospital Anna Meyer, University of Florence, Florence, Italy; and †Eisai Ltd, Hatfield, United Kingdom

Address correspondence to Renzo Guerrini, Children's Hospital Anna Meyer, University of Florence, Viale Pieraccini 24, 50139 Florence, Italy. E-mail: r.guerrini@meyer.it

Wiley Periodicals, Inc.

(C) 2014 International League Against Epilepsy
} 
The prevalence of epilepsy in children is approximately $0.5-0.7 \%{ }^{1}$ Although tolerability has improved with the development of newer antiepileptic drugs (AEDs), more than one fourth of pediatric patients remain refractory to medical therapy. ${ }^{2}$ Consequently, there is still a need for additional treatment options. Regulatory requirements for pediatric epilepsy have become increasingly stringent ${ }^{3,4}$ and relatively few well-designed, randomized-controlled trials have been performed in pediatric populations to date. ${ }^{5-10}$ A particularly important aspect of the evaluation of safety of a new agent in pediatric patients is the assessment of the effects of long-term treatment on growth and development. ${ }^{3}$

Zonisamide is a benzisoxazole derivative, chemically unrelated to other AEDs, with a variety of modes of action, including inhibition of $\mathrm{Na}^{+}$channels and reduction of T-type $\mathrm{Ca}^{2+}$ currents. ${ }^{11}$ It is currently licensed in Europe as monotherapy for the treatment of partial seizures (with or without secondary generalization) in adults with newly diagnosed epilepsy, and for the adjunctive treatment of partial seizures (with or without secondary generalization) in adults, adolescents, and children aged $\geq 6$ years. ${ }^{12}$ In the United States, it is currently licensed as adjunctive therapy in the treatment of partial seizures in adults with epilepsy. ${ }^{13}$

Results of a phase III, double-blind, randomized, placebo-controlled, multicenter trial have demonstrated that adjunctive treatment with zonisamide is significantly more effective than placebo in controlling seizures in pediatric patients with partial seizures who are receiving a stable regimen of one or two other AEDs; the proportion of patients experiencing $a \geq 50 \%$ reduction in seizure frequency from baseline after 12 weeks of maintenance treatment being $50 \%$ for zonisamide versus $31 \%$ for placebo $(p=0.0044$; intention-to-treat [ITT] population, last observation carried forward). ${ }^{10}$ Zonisamide was also shown to be well tolerated compared with placebo, with no new or unexpected safety findings observed in this setting. ${ }^{10}$

We present the results of an extension study conducted in patients completing the initial phase III trial, designed to investigate the safety/tolerability and efficacy of long-term adjunctive zonisamide treatment in pediatric patients with partial epilepsy, and to assess the impact of treatment on growth and development.

\section{Methods}

This was an open-label extension study of a phase III, double-blind, randomized, placebo-controlled, multicenter trial (Study 312$)^{10}$ that was conducted in order to assess the long-term safety/tolerability and explore the long-term maintenance of efficacy of adjunctive zonisamide treatment in pediatric patients (age 6-18 years) with partial epilepsy who were receiving one or two AEDs. Although the term "focal epilepsy" is now preferred by some investigators, ${ }^{14,15}$ the term "partial" is used for this extension study, for the sake of consistency with Study 312, which was conducted in the same patient cohort and used the term "partial." 10 The term "partial" is also still largely used within the neurologic community and by regulatory agencies. Patients were recruited from 28 sites in 10 European countries. The trial was conducted in accordance with Good Clinical Practice Guidelines and the protocol was approved by an independent ethics committee. All patients (or their guardian or legally authorized representative) provided written informed consent. The trial is registered with ClinicalTrials.gov, number NCT01136954.

\section{Patients}

The study included male and female patients, aged 6-18 years, who were willing to give informed assent (written or verbal), if applicable. If mandated by local regulations, patients of relevant age were also required to provide appropriate informed consent. In addition, patients had to have completed Study 312; have a parent/caregiver willing to provide informed consent (if the patient was under the age of consent); and be in general good health, as determined by medical history, physical examination, and screening laboratory results. Patients were excluded if they had a history of renal calculi or renal insufficiency (creatinine level $>135 \mu \mathrm{m}[1.5 \mathrm{mg} / \mathrm{dl}]$ ), or a history of demonstrated noncompliance with treatment. Patients were also excluded if they or their parent/guardian could reasonably be expected not to be compliant with the study procedures or to complete the study. Female subjects aged $\geq 10$ years or of childbearing potential (i.e., started menses) were excluded if not either using or willing to use a medically acceptable form of contraception (i.e., oral contraceptive pill, surgical sterilization, implant or injected form of contraception, or intrauterine device), or prepared to abstain from sexual activity for the duration of the study and for 1 month after last administration of study medication. If a female subject became of childbearing potential during the study, she had to be reconsented in order to undergo pregnancy testing, and either confirm abstinence or receive a medically appropriate form of contraception.

\section{Study design}

The extension study started with a double-blind transition period (duration 2-11 weeks) in order to preserve the blinding of Study 312, during which patients already receiving zonisamide continued on the same dose, while those who previously received placebo commenced zonisamide treatment, initiated at a dose of $1 \mathrm{mg} / \mathrm{kg} / \mathrm{day}$ and then up-titrated in weekly increments of $1 \mathrm{mg} / \mathrm{kg}$ to a target dose of $8 \mathrm{mg} /$ $\mathrm{kg}$ /day (maximum $500 \mathrm{mg} / \mathrm{day}$; Fig. S1). During the subsequent open-label period (duration 45-57 weeks), zonisamide dosing could be down-titrated, if required, in the event of an adverse event (AE), down to the minimum dose for the patient's weight group; and up-titrated again, if required, to control seizures, up to the maximum dose for the patient's 
weight group. The overall dose range was $1-8 \mathrm{mg} / \mathrm{kg} / \mathrm{day}$. The protocol assigned doses based on each patient's weight range ( 20 to $<29,29$ to $<42,42$ to $<56$, and $\geq 56 \mathrm{~kg}$ ). The weight ranges allowed a minority of patients whose weight was toward the higher end of each range to be dosed at $<8 \mathrm{mg} / \mathrm{kg} / \mathrm{day}$ and those whose weight was toward the lower end of each range to be dosed at $>8 \mathrm{mg} / \mathrm{kg} /$ day. The maximum permitted dose was $500 \mathrm{mg} /$ day. At the end of the study, patients could apply to continue zonisamide under the sponsor's compassionate use policy; otherwise, zonisamide dosing was down-titrated over a period of up to 4 weeks. The maximum total duration of the study was 59 weeks.

\section{Assessments}

\section{Safety and tolerability}

Safety assessments included the incidence of treatmentemergent AEs (TEAEs), serious TEAEs, and withdrawal due to TEAEs; clinical laboratory parameters (hematology, biochemistry, immune system, thyroid hormones); vital signs; and electrocardiography.

\section{Efficacy}

The primary efficacy assessment was the proportion of responders during the open-label period, where response was defined as a $\geq 50 \%$ decrease in 28-day seizure frequency from Study 312 baseline. Secondary efficacy assessments included the percentage change from Study 312 baseline in 28-day seizure frequency and the proportion of patients experiencing the following changes from Study 312 baseline in seizure frequency: 100\% decrease (seizure freedom), $\geq 75 \%$ decrease, $\geq 50 \%$ to $<75 \%$ decrease, $\geq 25 \%$ to $<50 \%$ decrease, no change to $<25 \%$ decrease, $>0 \%$ to $<25 \%$ increase, $\geq 25 \%$ to $<100 \%$ increase, and $\geq 100 \%$ increase.

\section{Growth and development}

Assessments of the impact of treatment on growth and development included Tanner stages (to assess sexual and endocrine maturation), hand x-rays (to assess skeletal development), Child Behavior Checklist for Children aged 6-18 (CBCL 6/18), School Performance questionnaire, Physician Global Impression of Change, Parent/Guardian Global Impression of Change, and Controlled Oral Word Association Test (COWAT). Tanner stages are scales ranging from 1 to 5 that assess how developed a subject is in puberty based on pubic hair (both males and females), genitals (males only), and breasts (females only). ${ }^{16,17}$ Stage 2 or above means that the subject has reached puberty. For assessment of skeletal development, posteroanterior projection X-rays were taken of each patient's left hand (including the wrist and distal radius), and the radiographs were analyzed centrally (Perceptive Informatics Inc, Berlin, Germany), with bone ages assigned by comparison with the atlas standards of Greulich and Pyle. ${ }^{18}$ The CBCL 6/18 comprises a questionnaire assessing specific competencies (20 items) and behavioral/emotional problems (118 items), as reported by the patient's parent/guardian. Scores are based on ratings by the parent/guardian for how true each item is "now or within the past 6 months" on a scale of $0-2$, where $0=$ "not true (as far as you know)," 1 = "somewhat or sometimes true," and 2 = "very true or often true." The School Performance questionnaire is a teacher-rated scale assessing effectiveness of learning, independent problem solving, remembering of instructions, retention of information, vocabulary, and hard working. Each patient is rated by their teacher on a scale from 1 ("among the lowest in his/her grade/year group/level") to 5 ("among the highest in his/her grade/year group/level"). The Physician and Parent/Guardian Global Impressions of Change consist of a single question ("Compared to the patient's condition at baseline, how much has the patient changed?"), where the patient's physician and parent/guardian rate change as "very much improved," "much improved," "minimally improved," "no change," "minimally worse," "much worse," or "very much worse." COWAT measures a patient's ability to make verbal association with specified letters and detects changes in word association fluency. It comprises two parts: Letter Fluency, where the patient is given 1 min to list as many words as possible beginning with a given letter $(\mathrm{F}, \mathrm{A}$, or $\mathrm{S})$; and Category Fluency, where the patient is given $1 \mathrm{~min}$ to list as many words as possible belonging to a given category (e.g., "animals"). COWAT was assessed only in patients with an intelligence quotient (IQ) of at least 75 .

\section{Statistics}

The safety population was defined as all patients who received at least one dose of study drug in the extension study. No sample size calculation was performed. For efficacy assessments, seizure frequency during a particular study period was calculated as the average 28-day seizure frequency during that period. Average 28-day seizure frequency was calculated using the following formula: average 28-day seizure frequency $=$ (number of seizures during yy days) $\times 28 / y y$. Responder rates $(\geq 50 \%$ decrease [primary assessment], $100 \%$ decrease, $\geq 75 \%$ decrease, $\geq 50 \%$ to $<75 \%$ decrease, $\geq 25 \%$ to $<50 \%$ decrease, no change to $<25 \%$ decrease, $>0 \%$ to $<25 \%$ increase, $\geq 25 \%$ to $<100 \%$ increase, and $\geq 100 \%$ increase) were calculated and presented with 95\% confidence intervals (CIs), calculated using the Clopper-Pearson method. Percentage change in 28-day seizure frequency was summarized using descriptive statistics and presented as median percentage change. Baseline and demographic data were summarized using descriptive statistics. The incidence and frequency of TEAEs were summarized using the Medical Dictionary for Regulatory Activities preferred terminology. Safety variables and assessments of growth and development were described using summary statistics; for these investigations, baseline 
was defined as the assessment prior to starting zonisamide treatment. Correlation between the Physician Global Impression of Change and Parent/Guardian Global Impression of Change was assessed using Pearson's correlation coefficient.

\section{Results}

\section{Patient population}

Between July 10, 2008, and March 8, 2012, a total of 144 patients from 28 sites in Belgium (1), Estonia (1), France (2), Hungary (5), Italy (1), Latvia (2), Poland (6), Spain (2), Ukraine (7), and the United Kingdom (1) entered the extension study, having first completed Study 312. Of these, 72 patients had received placebo during Study 312 and 72 had received zonisamide. All patients received at least one dose of study drug during the extension study, and were therefore included in the safety population. Overall, 99 (68.8\%) of 144 patients completed the study; reasons for discontinuation were lack of therapeutic efficacy $(n=27)$, withdrawal of consent $(n=8), \operatorname{AE}(s)(n=5)$, physician decision $(\mathrm{n}=1)$, and "other" (loss to follow-up, $\mathrm{n}=1$; below weight limit, $\mathrm{n}=1$; refusal to participate, $\mathrm{n}=1$; and consent form not signed, $\mathrm{n}=1$ ). For patients who discontinued due to lack of therapeutic efficacy or an AE, the median times to withdrawal were 168 and 357 days, respectively. Demographic and baseline characteristics were similar between patients who initially received zonisamide and placebo during Study 312, except that the proportion of male patients was slightly higher in the group that initially received placebo $(55.6 \%)$ compared with the group that initially received zonisamide $(43.1 \%$; Table $\mathrm{S} 1)$.

\section{Treatment exposure and dosing}

The mean (standard deviation [SD]) time that patients were in the extension study was 433.7 (169.9) days (median 444.5; range 15-721). Overall, 108 (75.0\%) of 144 patients were in the extension study for at least 1 year and exposed to zonisamide for at least 1 year. During the open-label period, the mean (SD) zonisamide dose was $7.5(1.1) \mathrm{mg} / \mathrm{kg} /$ day (median 7.5; range 3.8-10.6). Overall, 128 (88.9\%) of 144 patients received a dose of 5 to $<9 \mathrm{mg} / \mathrm{kg} /$ day during the open-label period; $2(1.4 \%)$ of 144 received a dose of 0 to $<5 \mathrm{mg} / \mathrm{kg} / \mathrm{day}$, and $8(5.6 \%)$ of 144 received a dose of 9-12 $\mathrm{mg} / \mathrm{kg} /$ day.

\section{Safety and tolerability}

During the transition, open-label, and down-titration periods, $41(28.5 \%)$ of $144,55(39.9 \%)$ of 138 , and $7(5.9 \%)$ of 118 patients reported at least one TEAE, respectively. During the study as a whole, $70(48.6 \%)$ of 144 patients reported at least one TEAE; the most frequently reported TEAEs were nasopharyngitis (10.4\%), headache (6.9\%), weight decreased (6.9\%), bronchitis $(5.6 \%)$, and decreased appetite (4.9\%; Table 1). TEAEs that were judged to be possibly or probably treatment related were reported by 39 (27.1\%) of 144 patients; most commonly, weight decreased (6.3\%), decreased appetite $(4.2 \%)$, and headache $(2.1 \%)$ (Table 1$)$. The majority of TEAEs were of mild or moderate intensity, and the incidence of TEAEs and treatment-related TEAEs was generally similar between patients who had initially received placebo and zonisamide in Study 312 (Table 1). The incidence of TEAEs was also similar between patients aged 6-11 years (34/67 [50.7\%]) and 12-18 years $(36 / 77$ [46.8\%]), and there were no TEAEs that were reported at a notably different frequency by age group (data not shown). Serious TEAEs were reported by $10(6.9 \%)$ of 144 patients, including three patients $(2.1 \%)$ who experienced serious TEAEs that were judged to be related to treatment. One patient experienced severe renal colic (probably related) and was withdrawn from the study, another patient experienced severe abdominal pain (possibly related) and was withdrawn from the study, and a third patient had a foot fracture of moderate intensity (possibly related) but continued in the study with no change in zonisamide dose. There were no deaths during the study. Four patients experienced TEAEs that led to discontinuation (one patient experiencing two TEAEs leading to discontinuation), but no specific TEAE led to the discontinuation of more than one patient (Table 1).

There were no clinically significant treatment-emergent laboratory abnormalities. Decreases in bicarbonate levels of $>3.5 \mathrm{~mm}$ were observed in 64 patients (44.4\%). Decreases in bicarbonate were generally small to moderate; the mean decrease from baseline (i.e., the assessment prior to starting zonisamide treatment) to final visit was $-1.8 \mathrm{~mm}$. A bicarbonate value of $\leq 16 \mathrm{~mm}$ and a decrease from baseline of $\geq 6 \mathrm{~mm}$ were observed in four patients $(2.8 \%)$, but no TEAEs of decreased bicarbonate were reported. A total of 24 patients $(16.7 \%)$ had a decrease in weight of $\geq 10 \%$ from baseline, and two patients $(1.4 \%)$ had a decrease in weight of $\geq 20 \%$ from baseline. There were no reports of serious rash or hypersensitivity reactions, and no vital signs or electrocardiographic parameters of clinical concern.

\section{Efficacy}

\section{Primary assessment}

During the open-label period, $81(56.3 \%)$ of 144 patients were responders $(\geq 50 \%$ reduction in 28-day seizure frequency from Study 312 baseline; 95\% CI 47.7-64.5\%; safety population; Table 2; Fig. S2). Results were similar for patients who initially received placebo in Study 312 (40/ $72 ; 55.6 \%$; 95\% CI 43.4-67.3\%) compared with those who initially received zonisamide $(41 / 72 ; 56.9 \%$; 95\% CI $44.7-$ 68.6\%; Table 2; Fig. S2).

\section{Secondary assessments}

During the open-label period, $16(11.1 \%)$ of 144 patients achieved seizure freedom $(100 \%$ reduction in 28 -day 


\section{R. Guerrini et al.}

\begin{tabular}{|c|c|c|c|}
\hline & $\begin{array}{l}\text { Placebo }^{a} \\
\mathrm{~N}=72\end{array}$ & $\begin{array}{l}\text { Zonisamide }^{b} \\
N=72\end{array}$ & $\begin{array}{l}\text { Total } \\
\mathrm{N}=144\end{array}$ \\
\hline Patients with TEAEs, n (\%) & $33(45.8)$ & $37(5 \mathrm{I} .4)$ & $70(48.6)$ \\
\hline \multicolumn{4}{|l|}{ TEAEs reported by $\geq 3 \%$ patients in any group, $n(\%)$} \\
\hline Nasopharyngitis & $6(8.3)$ & $9(12.5)$ & $15(10.4)$ \\
\hline Headache & $4(5.6)$ & $6(8.3)$ & $10(6.9)$ \\
\hline Weight decreased & $6(8.3)$ & $4(5.6)$ & $10(6.9)$ \\
\hline Bronchitis & $4(5.6)$ & $4(5.6)$ & $8(5.6)$ \\
\hline Decreased appetite & $5(6.9)$ & $2(2.8)$ & $7(4.9)$ \\
\hline Respiratory tract infection & $2(2.8)$ & $4(5.6)$ & $6(4.2)$ \\
\hline Rhinitis & $3(4.2)$ & $3(4.2)$ & $6(4.2)$ \\
\hline Abdominal pain & $2(2.8)$ & $3(4.2)$ & $5(3.5)$ \\
\hline Pharyngitis & $3(4.2)$ & $\mathrm{I}(\mathrm{I} .4)$ & $4(2.8)$ \\
\hline Pharyngolaryngeal pain & $3(4.3)$ & $\mathrm{I}(\mathrm{l} .4)$ & $4(2.8)$ \\
\hline Diarrhea & $\mathrm{I}(\mathrm{l} .4)$ & $3(4.2)$ & $4(2.8)$ \\
\hline Patients with treatment-related TEAEs, n (\%) & $19(26.4)$ & $20(27.8)$ & $39(27.1)$ \\
\hline \multicolumn{4}{|c|}{ Treatment-related TEAEs reported by $\geq 2 \%$ patients in any group, $n(\%)$} \\
\hline Weight decreased & $6(8.3)$ & $3(4.2)$ & $9(6.3)$ \\
\hline Decreased appetite & $4(5.6)$ & $2(2.8)$ & $6(4.2)$ \\
\hline Headache & 0 & $3(4.2)$ & $3(2.1)$ \\
\hline Complex partial seizures & $2(2.8)$ & 0 & $2(1.4)$ \\
\hline Aggression & $2(2.8)$ & 0 & $2(1.4)$ \\
\hline Rash papular & $2(2.8)$ & 0 & $2(1.4)$ \\
\hline Bradyphrenia & 0 & $2(2.8)$ & $2(1.4)$ \\
\hline \multicolumn{4}{|l|}{ Patients with treatment-related TEAEs by intensity, $\mathrm{n}(\%)$} \\
\hline Mild & $10(13.9)$ & $10(13.9)$ & $20(13.9)$ \\
\hline Moderate & $8(11.1)$ & $8(11.1)$ & $16(11.1)$ \\
\hline Severe & $\mathrm{I}(\mathrm{I} .4)$ & $2(2.8)$ & $3(2.1)$ \\
\hline Patients with serious TEAEs, $\mathrm{n}(\%)$ & $3(4.2)$ & $7(9.7)$ & $10(6.9)$ \\
\hline Patients with serious treatment-related TEAEs, n (\%) & $\mathrm{I}(\mathrm{l} .4)$ & $2(2.8)$ & $3(2.1)$ \\
\hline Patients with TEAEs leading to discontinuation, $\mathrm{n}(\%)$ & $2(2.8)$ & $2(2.8)$ & $4(2.8)$ \\
\hline \multicolumn{4}{|l|}{ TEAEs leading to discontinuation, $\mathrm{n}(\%)$} \\
\hline Nephrolithiasis & $\mathrm{I}(\mathrm{I} .4)$ & 0 & $\mathrm{I}(0.7)$ \\
\hline Renal colic & 0 & $\mathrm{I}(\mathrm{l} .4)$ & $\mathrm{I}(0.7)$ \\
\hline Ventricular extrasystoles & 0 & $\mathrm{I}(\mathrm{l} .4)$ & $\mathrm{I}(0.7)$ \\
\hline Abdominal pain & $\mathrm{I}(\mathrm{l} .4)$ & 0 & $\mathrm{I}(0.7)$ \\
\hline Status epilepticus & 0 & $\mathrm{I}(\mathrm{l} .4)$ & $\mathrm{I}(0.7)$ \\
\hline Patients with TEAEs leading to dose reduction, $\mathrm{n}(\%)$ & $4(5.6)$ & $3(4.2)$ & $7(4.9)$ \\
\hline $\begin{array}{l}\text { TEAE, treatment-emergent adverse event. } \\
{ }^{a} \text { Patients who received placebo during Study } 3 \mid 2 \text {. } \\
{ }^{b} \text { Patients who received zonisamide during Study } 3 \mid 2 \text {. }\end{array}$ & & & \\
\hline
\end{tabular}

Table 2. Grouped percentage changes from baseline in seizure frequency during the open-label period (safety population)

\begin{tabular}{|c|c|c|c|c|c|c|}
\hline \multirow[b]{2}{*}{ Change from Study 312 baseline in seizure frequency } & \multicolumn{2}{|c|}{$\begin{array}{l}\text { Placebo }^{a} \\
\mathrm{~N}=72\end{array}$} & \multicolumn{2}{|c|}{$\begin{array}{c}\text { Zonisamide }^{b} \\
N=72\end{array}$} & \multicolumn{2}{|c|}{$\begin{array}{c}\text { Total } \\
N=144\end{array}$} \\
\hline & $\mathrm{n}(\%)$ & $95 \% \mathrm{Cl}$ & $\mathrm{n}(\%)$ & $95 \% \mathrm{Cl}$ & $\mathrm{n}(\%)$ & $95 \% \mathrm{Cl}$ \\
\hline$\geq 50 \%$ decrease (primary assessment) & $40(55.6)$ & $43.4,67.3$ & $4 \mid(56.9)$ & $44.7,68.6$ & $8 \mathrm{I}(56.3)$ & $47.7,64.5$ \\
\hline $100 \%$ decrease (seizure freedom) & $8(I I . I)$ & $4.9,20.7$ & $8(I 1.1)$ & $4.9,20.7$ & $16(11.1)$ & $6.5,17.4$ \\
\hline$\geq 75 \%$ decrease & $27(37.5)$ & $26.4,49.7$ & $30(41.7)$ & $30.2,53.9$ & $57(39.6)$ & $31.5,48.1$ \\
\hline$\geq 50 \%$ to $<75 \%$ decrease & $13(18.1)$ & $10.0,28.9$ & II (I5.3) & $7.9,25.7$ & $24(16.7)$ & $11.0,23.8$ \\
\hline$\geq 25 \%$ to $<50 \%$ decrease & $10(13.9)$ & $6.9,24.1$ & $9(12.5)$ & $5.9,22.4$ & $19(13.2)$ & $8.1,19.8$ \\
\hline No change to $<25 \%$ decrease & $6(8.3)$ & $3.1,17.3$ & $9(12.5)$ & $5.9,22.4$ & $15(10.4)$ & $5.9,16.6$ \\
\hline$>0 \%$ to $<25 \%$ increase & $6(8.3)$ & $3.1,17.3$ & $2(2.8)$ & $0.3,9.7$ & $8(5.6)$ & $2.4,10.7$ \\
\hline$\geq 25 \%$ to $<100 \%$ increase & $5(6.9)$ & $2.3,15.5$ & $5(6.9)$ & $2.3,15.5$ & $10(6.9)$ & $3.4,12.4$ \\
\hline$\geq 100 \%$ increase & $\mathrm{I}(\mathrm{I} .4)$ & $0.0,7.5$ & $3(4.2)$ & $0.9,11.7$ & $4(2.8)$ & $0.8,7.0$ \\
\hline
\end{tabular}

$\mathrm{Cl}$, confidence interval.

${ }^{a}$ Patients who received placebo during Study 312.

${ }^{b}$ Patients who received zonisamide during Study 312. 
Long-Term Zonisamide in Children

Figure I.

Median percentage decrease in 28-day seizure frequency from Study 312 baseline during the extension study (safety population). OLV, open-label visit.

Epilepsia (C) ILAE

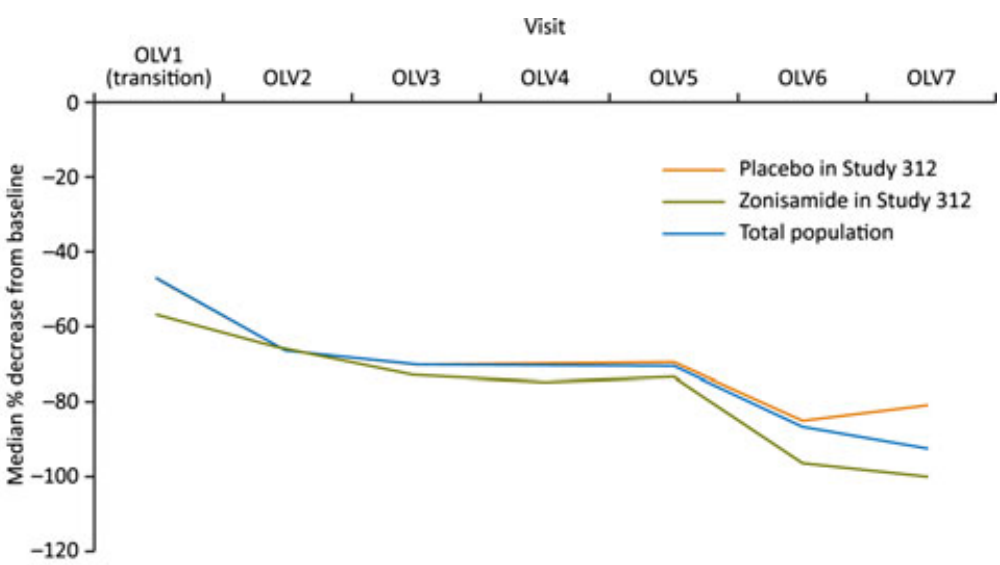

\begin{tabular}{|c|c|c|c|c|c|c|}
\hline$n=72$ & $n=68$ & $n=63$ & $n=57$ & $n=50$ & $n=32$ & $n=16$ \\
\hline$n=72$ & $n=69$ & $n=64$ & $n=58$ & $n=53$ & $n=31$ & $n=18$ \\
\hline$=144$ & $n=137$ & $n=127$ & $n=115$ & $n=103$ & $n=63$ & $n=34$ \\
\hline
\end{tabular}

seizure frequency from Study 312 baseline; 95\% CI 6.5$17.4 \%$; safety population; Table 2; Fig. S2). Results were identical for patients who initially received placebo and zonisamide in Study 312 (for both populations: 8/72; 11.1\%; 95\% CI 4.9-20.7\%; Table 2; Fig. S2). Results for other grouped percentage changes from baseline in seizure frequency demonstrated that $57(39.6 \%)$ of 144 patients experienced $\geq 75 \%$ reduction, $100 \quad(69.4 \%)$ of 144 patients experienced $\geq 25 \%$ reduction, and $14(9.7 \%)$ of 144 patients experienced $\geq 25 \%$ increase in seizure frequency from Study 312 baseline during the open-label period; values were similar for patients initially receiving placebo and zonisamide in Study 312 (Table 2).

The median percentage decrease in 28-day seizure frequency from Study 312 baseline was $48.1 \%$ during the transition period and $65.9 \%$ during the open-label period (safety population). Seizure frequency reduction was maintained throughout the extension study, and results were similar for patients who initially received placebo and zonisamide in Study 312 (Fig. 1).

\section{Growth and development}

\section{Tanner stages}

Results for Tanner stages for pubic hair, genitals (males only), and breasts (females only) were as expected for the study population, and no differences were observed between patients initially treated with placebo and zonisamide in Study 312 (Table S2A). Similarly, results for transitions between Tanner stages (Table S2B) and time between transitions of Tanner stages (data not shown) were as expected for the study population, with no differences observed between patients initially treated with placebo and zonisamide. Mean (SD; median; range) age at entrance of stage 2 (puberty) for pubic hair growth was $10.6(1.1 ; 11.0 ; 9-13)$ years for patients initially treated with placebo in Study 312,
$11.1(1.2 ; 11.0 ; 10-13)$ years for patients initially treated with zonisamide in Study 312, and 10.8 (1.2; 11.0; 9-13) years for the overall population. The corresponding values for age at entrance of stage 2 for genitals (males only) were $10.5(0.8 ; 11.0 ; 9-11), 11.5(2.4 ; 12.5 ; 8-13)$, and 10.9 (1.6; $11.0 ; 8-13)$ years, respectively; and for entrance of stage 2 for breasts (females only) were $9.5(1.3 ; 9.5 ; 8-11), 11.3$ $(0.6 ; 11.0 ; 11-12)$, and $10.3(1.4 ; 11.0 ; 8-12)$ years, respectively.

\section{Hand $x$-rays (skeletal development)}

Results for skeletal development (bone age and delay in maturation), before bone maturity and at bone maturity, were as expected for the study population (Fig. 2). Delays in bone maturation were minimal, and they were similar between patients initially treated with placebo and zonisamide in Study 312.

\section{CBCL 6/18}

Changes from baseline in CBCL 6/18 scores were minimal throughout the course of the study (Table 3). For example, median (mean) changes from baseline to open-label visit 5 (weeks 62-71) were $-1.0(-0.7)$ for Total Competence and $-2.0(-3.0)$ for Total Problems.

\section{School Performance questionnaire}

Changes from baseline in School Performance scores were minimal throughout the course of the study (Table S3).

\section{Physician and Parent/Guardian Global Impression of Change}

At all visits, the majority of patients for whom information was recorded were reported as having improved on both the Physician Global Impression of Change and the Parent/ Guardian Global Impression of Change, with good correlation between the scales (Table 4). For example, at 


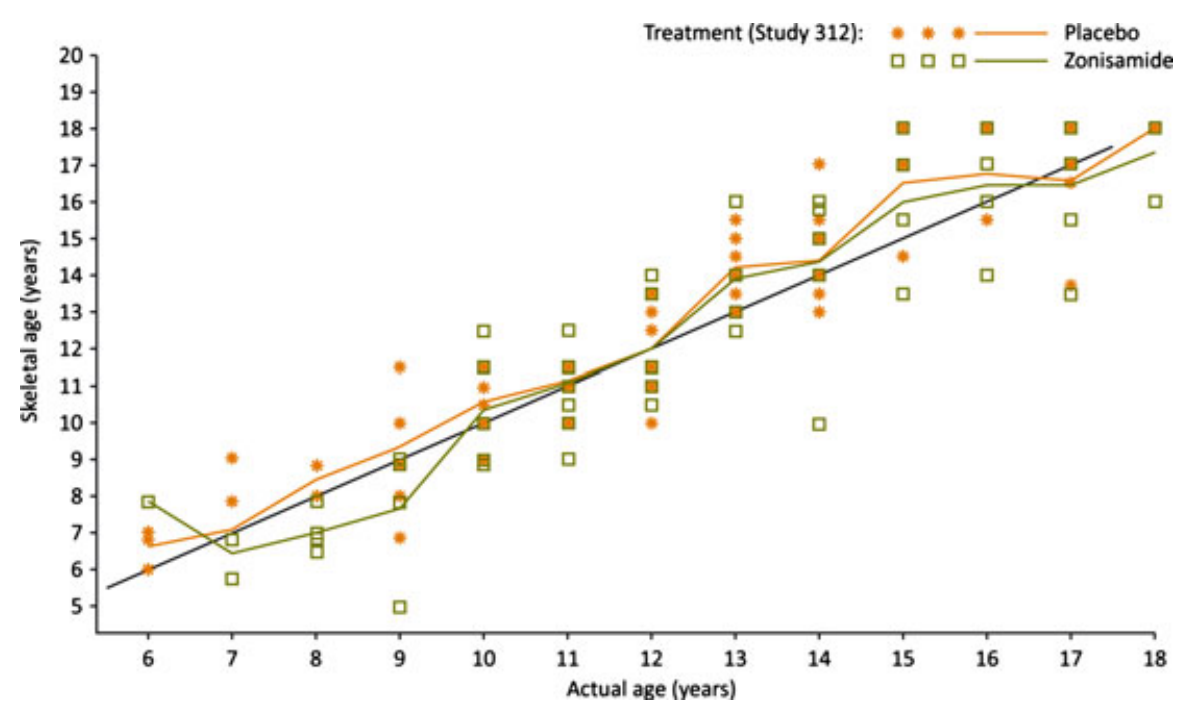

Figure 2.

Skeletal age and delay in maturation (safety population). Epilepsia (C) ILAE open-label visit 5 (weeks 62-71), the percentage of patients reported as "much improved"/"very much improved" was $73.8 \%$ on the Physician Global Impression of Change and $75.4 \%$ on the Parent/Guardian Global Impression of change, and the Pearson's correlation coefficient between the scales was 0.8980 .

\section{COWAT}

COWAT data were collected for 64 patients with an intelligence quotient of at least 75. Although there was a high degree of variability in the data, changes from baseline in Category Fluency and Letter Fluency were generally minimal, with no evidence of impairment with zonisamide treatment (Table S4). For example, median (mean) changes from baseline to open-label visit 5 (weeks 62-71) in Category Fluency and Letter Fluency scores were 2.0 (2.4) and $0.5(0.4)$, respectively.

\section{Discussion}

A key aspect of an AED's clinical development is to assess its safety and tolerability over the long term, since important safety signals can take time to emerge or occur too rarely to be picked up during the relatively short duration of the average phase III trial. The importance of this is illustrated by the increased risk of visual field defects associated with vigabatrin. This safety signal emerged only after the drug was being widely used in clinical practice, ${ }^{19}$ and was subsequently confirmed in a multinational, prospective, observational study. ${ }^{20}$ When assessing an AED's safety and suitability for use in the pediatric population, it is crucial to monitor additionally whether the agent has any effects on growth and development over the long term. ${ }^{3}$ It is also important to assess whether the efficacy of an AED is maintained long term, since patients can become tolerant to the beneficial effects of treatment. ${ }^{21}$ The present study-an open-label extension of one of only a few well-designed, randomized, controlled trials to have been conducted in the pediatric setting-provides information on the long-term safety and efficacy of adjunctive zonisamide therapy in pediatric patients with partial epilepsy. The study includes a thorough evaluation of the potential effects of zonisamide on growth and development, with three-fourths of those included in the study having been exposed to zonisamide treatment for at least 1 year.

The incidence of TEAEs in the extension study (49\%) was similar to that reported for patients treated with zonisamide and placebo in the initial trial $(55 \%$ and $50 \%$, respectively). ${ }^{10}$ The majority of TEAEs reported in the extension study were of mild or moderate intensity, and there was a low incidence of serious TEAEs and TEAEs leading to discontinuation. The most frequently reported treatment-related TEAEs were weight loss and decreased appetite, which is consistent with findings from the initial trial. ${ }^{10}$ This is also consistent with adjunctive and monotherapy studies conducted in adult patients ${ }^{12,22}$ : weight loss of $>5 \%$ occurring in approximately one third of adult patients treated with zonisamide, particularly those who are overweight prior to treatment. ${ }^{23}$ The mean decrease in bicarbonate levels observed in the extension study $(-1.8 \mathrm{~mm})$ is also consistent with the known safety profile for zonisamide. ${ }^{12}$ Overall, no new or unexpected safety findings emerged following long-term zonisamide treatment in this population.

This study also found that zonisamide displays no consistent detrimental effect on long-term growth and development, as assessed by Tanner stages, hand x-rays, CBCL 6/ 18, School Performance questionnaire, Physician Global Impression of Change, Parent/Guardian Global Impression of Change, and COWAT. This is a particularly important consideration when assessing a new treatment in the pediatric setting. ${ }^{3}$ Although cognitive assessments were limited to COWAT, it is encouraging that these results revealed no evidence of impairment with zonisamide treatment; a 


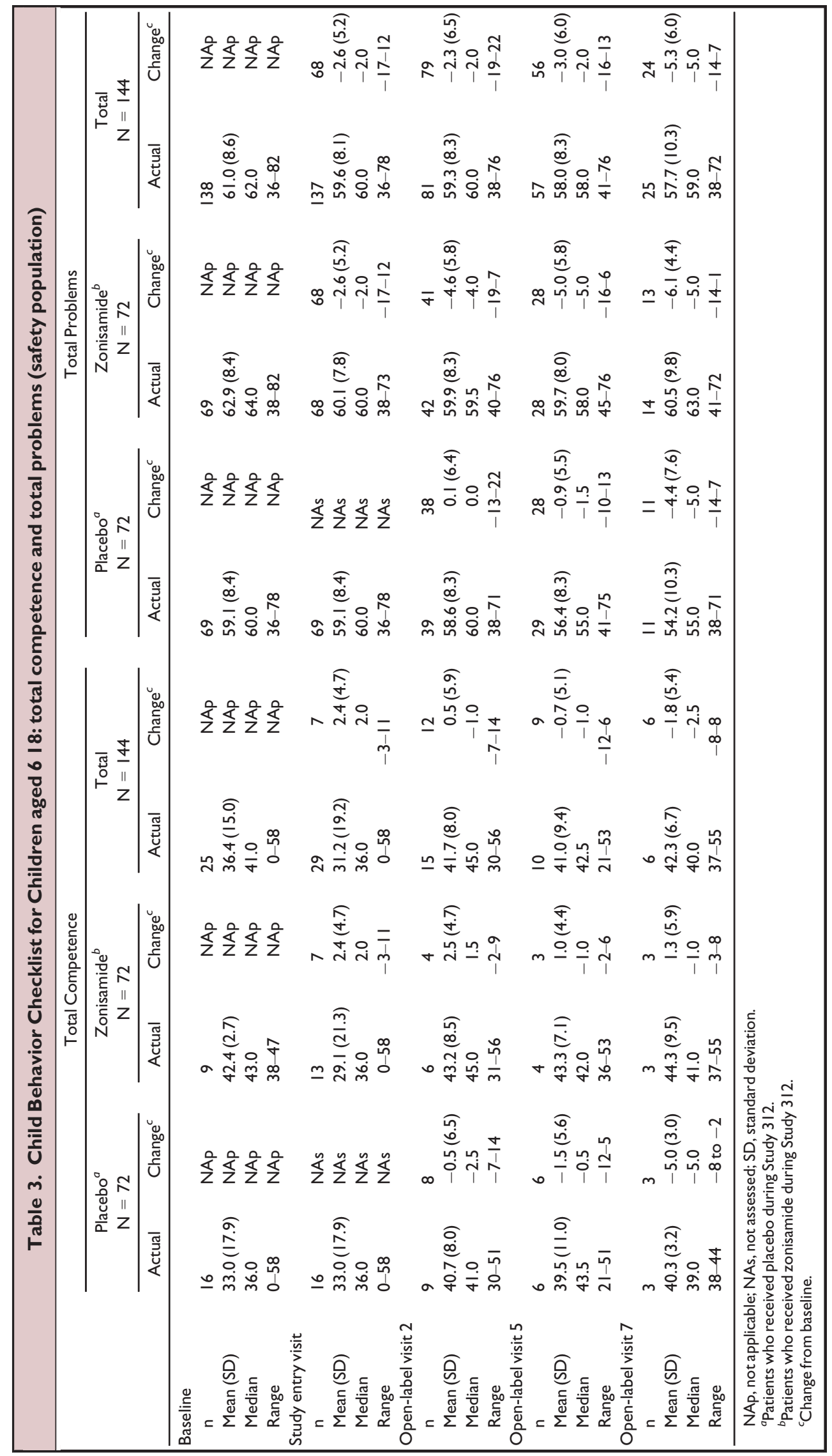


R. Guerrini et al.

\begin{tabular}{|c|c|c|c|c|c|c|c|}
\hline \multirow[b]{2}{*}{ Visit } & \multirow[b]{2}{*}{ Score } & \multicolumn{3}{|c|}{ Physician Global Impression of Change } & \multicolumn{3}{|c|}{$\begin{array}{l}\text { Parent/Guardian Global Impression of } \\
\text { Change }\end{array}$} \\
\hline & & $\begin{array}{l}\text { Placebo }^{a} \\
\mathrm{~N}=72\end{array}$ & $\begin{array}{l}\text { Zonisamide }^{b} \\
\mathrm{~N}=72\end{array}$ & $\begin{array}{c}\text { Total } \\
N=144\end{array}$ & $\begin{array}{l}\text { Placebo }^{a} \\
\mathrm{~N}=72\end{array}$ & $\begin{array}{l}\text { Zonisamide }^{b} \\
\mathrm{~N}=72\end{array}$ & $\begin{array}{c}\text { Total } \\
\mathrm{N}=144\end{array}$ \\
\hline \multirow[t]{10}{*}{ Open-label visit 2} & Not assessed & 0 & 0 & 0 & 0 & 0 & 0 \\
\hline & Very much improved, n (\%) & $8(16.3)$ & $13(26.5)$ & $2 \mathrm{I}(2 \mathrm{I} .4)$ & $8(16.3)$ & $16(33.3)$ & $24(24.7)$ \\
\hline & Much improved, n (\%) & $15(30.6)$ & $16(32.7)$ & $3 I(3 I .6)$ & $18(36.7)$ & $13(27.1)$ & $31(32.0)$ \\
\hline & Minimally improved, n (\%) & $12(24.5)$ & $7(14.3)$ & $19(19.4)$ & $7(14.3)$ & $6(12.5)$ & $13(13.4)$ \\
\hline & No change, $n(\%)$ & $9(18.4)$ & II (22.5) & $20(20.4)$ & $7(14.3)$ & $8(16.7)$ & $15(15.5)$ \\
\hline & Minimally worse, n (\%) & $5(10.2)$ & I (2.0) & $6(6.1)$ & $7(14.3)$ & $2(4.2)$ & $9(9.3)$ \\
\hline & Much worse, n (\%) & 0 & $I(2.0)$ & $I(I .0)$ & $I(2.0)$ & $2(4.2)$ & $3(3.1)$ \\
\hline & Very much worse, n (\%) & 0 & 0 & 0 & I (2.0) & $I(2 . I)$ & $2(2.1)$ \\
\hline & Missing & 13 & 17 & 31 & 14 & 18 & 32 \\
\hline & Pearson's correlation coef. & 0.9637 & & & & & \\
\hline \multirow[t]{10}{*}{ Open-label visit 3} & Not assessed & 0 & 0 & 0 & 0 & 0 & 0 \\
\hline & Very much improved, n (\%) & $6(17.1)$ & $14(36.8)$ & $20(27.4)$ & $7(20.0)$ & $17(44.7)$ & $24(32.9)$ \\
\hline & Much improved, n (\%) & $18(5 \mid .4)$ & $15(39.5)$ & $33(45.2)$ & $17(48.6)$ & II (29.0) & $28(38.4)$ \\
\hline & Minimally improved, n (\%) & $5(\mid 4.3)$ & $4(10.5)$ & $9(12.3)$ & $5(\mid 4.3)$ & $4(10.5)$ & $9(12.3)$ \\
\hline & No change, $n(\%)$ & $4($ (II.4) & $4(10.5)$ & $8(I I .0)$ & $4(11.4)$ & $6(15.8)$ & $10(13.7)$ \\
\hline & Minimally worse, n (\%) & $2(5.7)$ & $\mathrm{I}(2.6)$ & $3(4.1)$ & $2(5.7)$ & 0 & $2(2.7)$ \\
\hline & Much worse, n (\%) & 0 & 0 & 0 & 0 & 0 & 0 \\
\hline & Very much worse, n (\%) & 0 & 0 & 0 & 0 & 0 & 0 \\
\hline & Missing & 15 & 18 & 33 & 15 & 18 & 33 \\
\hline & Pearson's correlation coef. & 0.9867 & & & & & \\
\hline \multirow[t]{10}{*}{ Open-label visit 5} & Not assessed & 0 & 0 & 0 & 0 & 0 & 0 \\
\hline & Very much improved, n (\%) & $6(20.0)$ & II (35.5) & $17(27.9)$ & $9(30.0)$ & $10(32.3)$ & $19(3 \mid .2)$ \\
\hline & Much improved, n (\%) & $16(53.3)$ & $12(38.7)$ & $28(45.9)$ & $13(43.3)$ & $14(45.2)$ & $27(44.3)$ \\
\hline & Minimally improved, n (\%) & $4(13.3)$ & $4(12.9)$ & $8(13.1)$ & $4(13.3)$ & $3(9.7)$ & $7(11.5)$ \\
\hline & No change, $n(\%)$ & $2(6.7)$ & $2(6.5)$ & $4(6.6)$ & 0 & $2(6.5)$ & $2(3.3)$ \\
\hline & Minimally worse, n (\%) & $2(6.7)$ & $2(6.5)$ & $4(6.6)$ & $3(10.0)$ & $2(6.5)$ & $5(8.2)$ \\
\hline & Much worse, n (\%) & 0 & 0 & 0 & I (3.3) & 0 & I (I.6) \\
\hline & Very much worse, n (\%) & 0 & 0 & 0 & 0 & 0 & 0 \\
\hline & Missing & 0 & 0 & 0 & 0 & 0 & 0 \\
\hline & Pearson's correlation coef. & 0.8980 & & & & & \\
\hline \multirow{10}{*}{ Open-label visit 7} & Not assessed & 0 & 0 & 0 & 0 & 0 & 0 \\
\hline & Very much improved, n (\%) & $3(23.1)$ & $10(71.4)$ & $13(48.2)$ & $3(23.1)$ & $10(71.4)$ & $13(48.2)$ \\
\hline & Much improved, n (\%) & $7(53.9)$ & $2(14.3)$ & $9(33.3)$ & $6(46.2)$ & $2(14.3)$ & $8(29.6)$ \\
\hline & Minimally improved, n (\%) & I (7.7) & I (7.I) & $2(7.4)$ & $3(23.1)$ & I (7.I) & $4(14.8)$ \\
\hline & No change, $n$ (\%) & I (7.7) & I (7.I) & $2(7.4)$ & 0 & I (7.I) & $\mathrm{I}(3.7)$ \\
\hline & Minimally worse, n (\%) & I (7.7) & 0 & I (3.7) & I (7.7) & 0 & I (3.7) \\
\hline & Much worse, n (\%) & 0 & 0 & 0 & 0 & 0 & 0 \\
\hline & Very much worse, n (\%) & 0 & 0 & 0 & 0 & 0 & 0 \\
\hline & Missing & 0 & 0 & 0 & 0 & 0 & 0 \\
\hline & Pearson's correlation coef. & 0.9347 & & & & & \\
\hline
\end{tabular}

finding that is supported by the lack of any effect on the School Performance questionnaire.

During the open-label treatment period, the proportion of responders (patients showing $\geq 50 \%$ seizure frequency reduction from baseline in the initial trial) was $56 \%$, consistent with the responder rate observed in the initial trial $(50 \%),{ }^{10}$ indicating that the efficacy of zonisamide is maintained with long-term treatment. This is further illustrated by the fact that the median decrease in 28-day seizure frequency observed in the maintenance period of the initial trial $(50 \%)$ was maintained throughout the extension study (Fig. 1), the median decrease during the open-label period being $66 \%$. The proportion of patients achieving seizure freedom during the open-label period was $11 \%$, which was also consistent with the $14 \%$ seizure freedom rate observed in the initial trial. ${ }^{10}$

A potential limitation of this study was that growth and development were assessed over a relatively short duration of treatment (approximately 1 year), and consequently the findings provide a useful snapshot of only the potential effects of treatment on patients' longer-term growth and development. However, these parameters were additionally monitored in the initial trial (median duration of treatment exposure, 140 days $)^{10}$ and it is encouraging that, overall, 
there has been no indication of any consistent detrimental effects on growth and development with adjunctive zonisamide treatment. These findings will need to be clarified further with longer-term observation. As with any multicenter, multinational investigation, another potential limitation of this study was the probable heterogeneity of the study population as a result of regional variation; however, this did not appear to affect the robustness of the initial trial's findings. ${ }^{10}$ In addition, as an open-label extension of a previous trial, this study is limited as it does not have a comparator for zonisamide over the long term. It is also limited by the different durations of zonisamide exposure experienced by patients treated with zonisamide and placebo in the initial trial. Nevertheless, it provides valuable information regarding the long-term effects of adjunctive treatment with zonisamide in the pediatric population.

In summary, this extension study demonstrates that adjunctive zonisamide therapy is well tolerated and efficacious when administered to pediatric patients with partial epilepsy over a treatment period of at least 1 year. No new or unexpected safety concerns emerged, and there was no indication of any consistent detrimental effects on longterm growth and development. Zonisamide could therefore prove to be a valuable treatment option for pediatric patients with partial epilepsy.

\section{ACKNOWLEDGMents}

This study was funded by Eisai Ltd. Editorial support (checking of data, technical editing, copyediting, and preparation of tables and figures) was provided by Harjinder Chahal of $\mathrm{mXm}$ Medical Communications.

The trial's Principal Investigators were the following: Renzo Guerrini (Principal Investigator of whole study), Mykola Aryayev (Ukraine), Boglárka Bánsági (Hungary), Nicolas Deconinck (Belgium), Ewa EmichWidera (Poland), Renzo Guerrini (Italy), Ilona Gyorgy (Hungary), José Luis Herranz (Spain), Katalin Hollódy (Hungary), Nahin Hussain (United Kingdom), Sergiusz Jóźwiak (Poland), Mária Kassay (Hungary), Irina Makedonskaya (Ukraine), Grazyna Martynowska (Poland), Lydiya Maryenko (Ukraine), Maria Mazurkiewicz-Bełdzińska (Poland), Sergii Moskovko (Ukraine), Magda Neuwirth (Hungary), Dominique Parain (France), Jean-Marc Pinard (France), Mykola Pityk (Ukraine), Tetyana Proskurina (Ukraine), Guntis Rozentals (Latvia), Maria Victoria San Antonio Arce (Spain), Barbara Steinborn (Poland), Inga Talvik (Estonia), Baiba Uskane (Latvia), Imre Velkey (Hungary), Petro Voloshyn (Ukraine), and Stanislawa Watrobska (Poland).

\section{Disclosure or Conflicts of INTEREST}

Dr. Guerrini has received honoraria from Biocodex, UCB, Eisai Inc, ValueBox, and Viropharma. He has received research support from the Italian Ministry of Health, the European Community Sixth Framework Thematic Priority Life Sciences, Genomics and Biotechnology for Health, the E-Rare EU project program, the Italian Ministry of Education, University and Research, the Tuscany Region, the Pisa Foundation, the Telethon Foundation, and the Mariani Foundation. Dr. Rosati reports no disclosures. Ms. Bradshaw and Dr. Giorgi are employees of Eisai Ltd. Editorial support (as outlined in Acknowledgments) was funded by Eisai Ltd. We confirm that we have read the Journal's position on issues involved in ethical publication and affirm that this report is consistent with those guidelines.

\section{REFERENCES}

1. Connock M, Frew E, Evans BW, et al. The clinical effectiveness and cost-effectiveness of newer drugs for children with epilepsy. A systematic review. Health Technol Assess 2006;10:iii, ix-118.

2. Guerrini R. Epilepsy in children. Lancet 2006;367:499-524.

3. Garofalo E. Clinical development of antiepileptic drugs for children. Neurotherapeutics 2007;4:70-74.

4. Chiron C, Dulac O, Pons G. Antiepileptic drug development in children: considerations for a revisited strategy. Drugs 2008;68: $17-25$.

5. Appleton R, Fichtner K, LaMoreaux L, et al. Gabapentin as add-on therapy in children with refractory partial seizures: a 12-week, multicentre, double-blind, placebo-controlled study. Gabapentin Paediatric Study Group. Epilepsia 1999;40:1147-1154.

6. Duchowny M, Pellock JM, Graf WD, et al. A placebo-controlled trial of lamotrigine add-on therapy for partial seizures in children. Lamictal Pediatric Partial Seizure Study Group. Neurology 1999;53:1724-1731.

7. Elterman RD, Glauser TA, Wyllie E, et al. A double-blind, randomized trial of topiramate as adjunctive therapy for partial-onset seizures in children. Topiramate YP Study Group. Neurology 1999;52:1338-1344.

8. Glauser TA, Nigro M, Sachdeo R, et al. Adjunctive therapy with oxcarbazepine in children with partial seizures. The Oxcarbazepine Pediatric Study Group. Neurology 2000;54:2237-2244.

9. Glauser TA, Ayala R, Elterman RD, et al. Double-blind placebocontrolled trial of adjunctive levetiracetam in pediatric partial seizures. Neurology 2006;66:1654-1660.

10. Guerrini R, Rosati A, Segieth J, et al. A randomized, phase III trial of adjunctive zonisamide in pediatric patients with partial epilepsy. Epilepsia 2013;54:1473-1480.

11. Biton V. Clinical pharmacology and mechanism of action of zonisamide. Clin Neuropharmacol 2007;30:230-240.

12. Zonegran ${ }^{\circledR}$ summary of product characteristics. Eisai Ltd, 2013. Available at:http://www.medicines.org.uk/emc/medicine/16240/SPC/ Zonegran\%20capsules. Accessed November 5, 2013.

13. Zonegran ${ }^{\circledR}$ prescribing information. Eisai Inc, 2012. Available at: http://us.eisai.com/wps/wcm/connect/eisai/Home/resources/b2b5f480 4fdfb73aa26da2c7586bf6dd/Zonegran_PI.pdf. Accessed November $5,2013$.

14. Engel J Jr. A proposed diagnostic scheme for people with epileptic seizures and with epilepsy: report of the ILAE Task Force on Classification and Terminology. International League Against Epilepsy (ILAE). Epilepsia 2001;42:796-803.

15. Berg AT, Berkovic SF, Brodie MJ, et al. Revised terminology and concepts for organization of seizures and epilepsies: report of the ILAE Commission on Classification and Terminology, 2005-2009. Epilepsia 2010;51:676-685.

16. Marshall WA, Tanner JM. Variations in pattern of pubertal changes in girls. Arch Dis Child 1969;44:291-303.

17. Marshall WA, Tanner JM. Variations in the pattern of pubertal changes in boys. Arch Dis Child 1970;45:13-23.

18. Greulich WW, Pyle SI. Radiographic atlas of skeletal development of the hand and wrist. 2nd Ed. Stanford, CA: Stanford University Press; 1959.

19. Lawden MC, Eke T, Degg C, et al. Visual field defects associated with vigabatrin therapy. J Neurol Neurosurg Psychiatry 1999;67:716-722.

20. Wild JM, Ahn HS, Baulac M, et al. Vigabatrin and epilepsy: lessons learned. Epilepsia 2007;48:1318-1327.

21. Löscher W, Schmidt D. Experimental and clinical evidence for loss of effect (tolerance) during prolonged treatment with antiepileptic drugs. Epilepsia 2006;47:1253-1284.

22. Baulac M, Brodie MJ, Patten A, et al. Efficacy and tolerability of zonisamide versus controlled-release carbamazepine for newly diagnosed partial epilepsy: a phase 3, randomised, double-blind, noninferiority trial. Lancet Neurol 2012;11:579-588.

23. Wellmer J, Wellmer S, Bauer J. The impact of zonisamide on weight. A clinical study in 103 patients with epilepsy. Acta Neurol Scand 2009;119:233-238. 


\section{R. Guerrini et al.}

\section{SuPPORTING INFORMATION}

Additional Supporting Information may be found in the online version of this article:

Fig. S1. Study design.

Fig. S2. Responder rate ( $\geq 50 \%$ reduction in 28-day seizure frequency from Study 312 baseline) and seizure freedom rate (100\% reduction in 28-day seizure frequency from Study 312 baseline) during the open-label period (safety population).
Table S1. Patient demographics and baseline characteristics (safety population).

Table S2. (A) Tanner stages at baseline, study entry, and open-label visit 3 (weeks 40-43) and (B) transitions between Tanner stages (increases in one group) from baseline to study entry and open-label visit 3 (weeks 40-43; safety population).

Table S3. School Performance (safety population).

Table S4. Controlled Oral Word Association Test (patients with an intelligence quotient of at least 75 ; safety population). 